\title{
A New Paradigm Relating Art and Sport
}

\author{
Danny Shorkend \\ WIZO School of Design, Haifa, Israel \\ Email: dannyshorkend@yahoo.co.uk
}

How to cite this paper: Shorkend, D. (2019). A New Paradigm Relating Art and Sport. Advances in Physical Education, 9, 23-41.

https://doi.org/10.4236/ape.2019.91003

Received: November 7, 2018

Accepted: January 5, 2019

Published: January 8, 2019

Copyright $\odot 2019$ by author and Scientific Research Publishing Inc. This work is licensed under the Creative Commons Attribution International License (CC BY 4.0).

http://creativecommons.org/licenses/by/4.0/

\begin{abstract}
In this article, I outline ways in which sport can be reconsidered as drawing aesthetic and philosophical depth from the rarefied domain of art. I do this by arguing that sport, as an everyday aesthetics, is an extension of art aesthetics and this is given further weight by Gumbrecht's argument that indeed sport is formally beautiful, drawing on its artistic heritage as such. I offer three basic underpinnings for such a perspective, namely aesthesis, play and empathy. In so doing, the dialectic between art and sport promises a cross-pollination and inter-disciplinary venture that has both theoretical and practical implications.
\end{abstract}

\section{Keywords}

Art, Sport, Body, Beauty, Play, Aesthesis, Empathy

\section{Introduction}

This article consists of four movements towards the goal of laying a foundation for a new paradigm wherein art and sport overlap. This is achieved by firstly and briefly outlining the historical impasse in art wherein art was separated from the everyday (Section 1), followed by the more recent move to the contrary, namely aesthetics of the everyday (Section 2). This then goes some way to arguing that indeed sport shares certain aesthetic modalities with art, an argument that is given some weight with the work of Gumbrecht in his somewhat seminal "In praise of athletic beauty" (Section 3). Then in some detail, I further demonstrate overlaps between art and sport through the philosophical concepts of aesthesis, empathy and play (Section 4).

While modernism has often been understood as isolating and demarcating various forms of cultural expression, be art or science, there has been a trend to develop interdisciplinary or transdisciplinary modes of understanding. In this respect, I believe it is timely and significant to develop an appraisal of sport from 
an arts perspective.

My task then is to show how art-related aesthetics can be useful to explain and develop sport theory in a new way. "New" in the sense that an affinity between the two is described and argued for, although this has been somewhat developed in the recent past in the 1970s and 1980s triggered by Reid (1970), Kupfer (2001), Best (1979, 1986), Best (1979), Wertz (1984) and Cordner (1988). My intention or contribution is, unlike these writers, not a concern with the question whether sport is art, but simply developing a theoretical framework that motivates the theoretical overlap between art-related aesthetics and sport. Such an overlap-whether aesthetic, extra-aesthetic-may enhance our experience (in art and in sport as in life). This implies a "third concept" (a trans disciplinary field), which would explain the endless oscillation, but one which is potentially dialectical, so that in that process there is a beautiful "wrestling", even a "wrestling" with the concept of "beauty" itself.

The paradigm shift in philosophical thinking which Shusterman (2008: p. 8) neatly describes as a "vision of an essentially situated, relational, and symbiotic self rather than the traditional concept of an autonomous self grounded in an individual, monadic, indestructible and unchanging soul" implies that there is always some aspect of the body (or rather somo-the living body) in the understanding of persons and aspects of world. The dominant Platonic-ChristianCartesian tradition is thus challenged by the fact that we think and act through our bodies so that in Shusterman's (2008: p. 19) words: "if the body is our primordial instrument in grasping the world, then we can learn more of the world by improving the conditions and use of this instrument”. In view of this it seems natural to turn philosophical attention on sport, a bodily activity.

\section{The Neglect of Everyday Aesthetics and toward a New Interpretation of Sport}

A basic summary by way of introduction of art-aesthetics is in order so that one can argue in what respect sport theory could be perceived in a new light.

Whereas, one finds in the eighteenth century Western aesthetic tradition that fine art was not thought of in isolation, but thought of in broader terms, that is as encompassing everyday aesthetic matters, one finds in the nineteenth century and the first half of the twentieth century an obsession, so to speak, with aesthetics as it pertained to fine arts. However, in the latter part of the twentieth century and now of current concern one note that a shift has occurred in that there is precisely a reappraisal of the aesthetics of the everyday. Yet, even so sport has received scant attention, particularly in terms of an art-aesthetic perspective.

Literature on sport, a rather recent academic pursuit (around the 1960's; save the alignment of art and sport recognised by the Ancient Greeks) deals with philosophical aspects, social sciences, history (of sport), sports sciences, management and even psychology, but there is a dearth of texts that relate art to 
sport. One reason why this might be the case is that art-related aesthetics has been so confined to art as an autonomous sphere, as some kind of isolated, "disinterested" experience such that a reciprocity between the two fields was not interrogated. While some theorists such as Reid (1970), Kupfer (2001), Best (1974, 1978, 1986), Wertz (1984), Welsch (2005) and others did engage with the question "Is sport art?" and deduced various answers, the question itself is flawed somewhat as it assumes that a kind of "essence" pertains to both. Instead what I maintain and argue for, what in fact is a gap in the literature and a contribution to this field of inquiry is precisely that the implications for an everyday aesthetic such as sport in fact may derive its meaning from an art-based conceptual schema. In contradistinction to simply a philosophical or general aesthetic schema, this promises a "new" and original departure wherein sport so conceived is partially continuous with art, a "weak" version of everyday aesthetics as I shall develop below.

\section{Everyday Aesthetics}

A number of new sub-disciplines in aesthetics have recently been identified or rediscovered. Ratiu (2013: pp. 5-8) notes that there are a number of trends linking aesthetics to the everyday, such as "participatory aesthetics" and "social aesthetics" by Berleant as an alternative to aesthetics as a "disinterested" experience; aesthetics of the human environment by Berleant and Carlson; "pragmatist aesthetics" (or somaesthetics) by Shusterman, such as popular music and film and arts of self-realization; "aesthetic multiculturalism" by Sartwell and others, dealing with art of cultures other than the West wherein aesthetics and everyday life are enmeshed and the area that I am concerned with, namely "aesthetics of the everyday" (or AEL), the aesthetics of virtually all aspects of daily life, sport being one such example. Having said this, Irvin (2008: p. 29f) notes that fewer than two percent of articles in the British Journal of Aesthetics and the Journal of Aesthetics and Art Criticism between 2001-2006, dealt with aesthetic topics other than art. I do not have the figures for more recent trends, but it is clear that more voices on the subject are needed. This is surprising, because arguably the "founding father" of everyday aesthetics, that of Dewey, in his breaking down the distinction between aesthetic experiences in art with other experiences, already pre-empted this direction in aesthetics, writing a number of decades ago. Furthermore, the Journal of the Philosophy of Sport has for decades recognized the philosophical and even artistic dimension of sport and I foresee the "playing fields" in art criticism will be influenced by such endeavours.

Aesthetics of the everyday is the study of everyday life towards its appraisal as aesthetic. Which aspects of everyday life fit into this category and whether art aesthetics is significant in extending it, is a current point of debate. Christopher Dowling (2010) suggests that this new sub-discipline can be divided into two distinctive camps:

$A D L I$ (Weak): The concept of the aesthetic, at work in discussions of the value 
of art can be extended to include experiences from daily life.

ADLI (Strong): Experiences from daily life can afford paradigm instances of aesthetic experience. Such experiences are not bound by the limitations and conventions of aesthetic value in the philosophy of art (adapted from Dowling, 2010: p. 226, ADLI stands for "aesthetics of everyday life intuition").

Dan Ratiu (2013), Christopher Dowling (2010) and Sherri Irvin (2008) align themselves with the weak formulation, while Yuriko Saito (2007) and Kevin Melchionne (2011) argue for the "strong" version. This divergence is as a result of their respective definitions of what constitutes an everyday aesthetics. Since I am arguing for a somewhat of a continuum embracing art and sport, derived from an aesthetic no less than an extra-aesthetic dimension, I do not consider the aesthetics of sport as insulated in the same way art was considered "arts for arts sake"-rather there is a dialectical inter-penetration between such domains.

Ratiu (2013: p. 4) opposes the traditional conflation of the aesthetic dimension with the artistic institution that is "then insulated from ordinary human life and experience". Instead, he wishes to address the aesthetics of ordinary life ${ }^{1}$ as well as built environments and popular art in such a way that art-related aesthetics and the everyday interact. Having discerned qualities that may apply to art and the everyday, Ratiu (2013: p. 20) writes: “...these concepts are useful in developing a consistent aesthetic theory able to accommodate both art and everyday life and their interaction. In this way, the distinction between art-related experiences and non-art daily aesthetic experiences is less sharp than pretended by AEL-strong, while these experiences do resemble each other in some features".

Dowling (2010) has a similar definition of everyday aesthetics. He argues that the aesthetics of daily life intuition is "...one expressed by those quite familiar with the concept of the aesthetic as it occurs in the art world and adamant that this aspect of our experiences of art should be recognized as characteristic of many quotidian contexts" (Dowling, 2010: p. 230). He maintains this position by arguing that elements usually associated with art are not necessarily in contradistinction to the everyday such that art may also, like the everyday be about practicalities, impermanence and the multi-sensory.

Irvin (2008) takes this sharing of qualities between art and the everyday further by applying Dewey's definition of an experience, as one that contains unity and closure, with the following assertion (2008: p. 33) "An experience of a symphony or a Victorian novel is very likely to be characterized by unity and closure as Dewey describes it. It seems that the description might also apply to an intense sexual experience, or to the experience of running a race or climbing a

\footnotetext{
${ }^{1}$ Ratiu (2013: p. 7) writes: "The scope of aesthetics is expanded to include areas of everyday life previously neglected-consumer goods, artifacts, the urban or suburban built environments, and the ambiance within which we interact on a daily basis, including weather, other domains of life such as sport, sex, and everyday decision-making, as well as the ordinary domestic practices of dwelling and house-making such as cleaning, discarding, purchasing, using tools, cooking, dressing up, resting/relaxing and so on".
} 
mountain". However, later in her article on the "pervasiveness of the aesthetic in ordinary experience" (2008) she argues that everyday life as well as art may lack unity or closure, may be simple and may contain elements that reside in the subconscious. In this light, consider Irvin's Zen-like description of aesthetic experiences that, should we so choose, may be found readily:

...Being in the room you are in right now, with its particular visual features and sounds; sitting the way you are sitting, perhaps crookedly in an uncomfortable chair; feeling the air currents on your skin-all of these things impart a texture to your experience, that... should be regarded as aesthetic...

The reader will notice that this kind of attentiveness is also often a precondition for the artist in relation to his/her subject as well as the viewer in relation to the art-object. A similar focus may be required for sport. This may be understood by the following seeming digression on Zen or mindfulness, before continuing to define everyday aesthetics in order to give weight to the "weaker-version": Mindfulness occurs when the body is at rest but it can also occur at the liminal point where one's senses are alert or when doing a particular activity and one is "lost in focused intensity" (the swimmer Morales quoted in Gumbrecht, 2006: p. 49). Dispensing with the notion of beauty in art, we reconstruct beauty and aesthetic experience as potentially all-pervasive, the field of numerous activities. In this regard, to be "lost in focused intensity" is to impute an aesthetic dimension and reapplication of the idea of beauty to an art of living. The idea that one can paint highly expressive works of "genius" but in life proper one is simply not a nice person is antiquated and looses a sense of the significance of art and aesthetics in terms of self-actualization and social-ethical responsibility. In this sense, the tendency in contemporary art to draw on a number of areas of life, sport included is a "good move", as are collaborative projects within and beyond the arts, working together from diverse nationalities and showcased at, for example, a biennale-a sports-like happening/event/game that perhaps both unifies and acknowledges difference.

Melchionne, as with Saito, argues for the "strong-version", and points out that Dowling makes the mistake of "focusing on discrete moments... [he has] mistaken the very ontology of everyday aesthetic life. What matters is the routine, habit, or practice, the cumulative rather than the individual effect" (Melchionne, 2011: p. 439). Melchionne errs perhaps in thinking that art itself may not share some of those characteristics associated with an everyday aesthetic, for example its commonness, and he defines everyday aesthetics in terms of practices such as cleaning, homemaking, cooking and wardrobe. Such common, repetitive activities are accordingly distinguished from "disinterested", autonomous art. Furthermore, Melchionne rejects the role of discourse in everyday aesthetics. Rather, it is of such a type, that it is unmediated, sensory experience. Ratiu argues that in the light of the poststructural denial of pure, unmediated direct per- 
ception, this would be a difficult line to maintain. Besides, we do contend, as Dowling rightly points out, that we argue with others over appearances, "insisting that one's aesthetic estimations should be acknowledged and respected" (Ratiu, 2013: p. 23), that is, that discourse is built into aesthetic experience. Moreover, critical discourse, say the "game" of art criticism or the "game" of sports commentary, aids understanding and appreciation, even making effable the seemingly ineffable that is aesthetic experience of whatever kind.

If one were to maintain the "strong version", if they were simply described as oppositions-art as coherent, as expressing ideas (that is, as having "depth") and everyday aesthetics as "surface" - what would be the satisfaction, the aesthetic joy in the everyday in the first place? There would be no creative dialectic, and no connection between them, but what of their interface, for example in popular culture (cultural studies). So the strong version would "disallow" the research of popular art (such as film and television) as part of an everyday aesthetic, but this may be incorrect, as in the life-world, mass culture and routine everyday experiences often coincide. Sport, I maintain, seems to belong in this category (as part of mass culture), and as with film and television (for example) imports artistic concepts. Only the weak version adequately deals with this possibility.

Moreover, proponents of the "strong" version have a problem with the "weak" formulation as it elevates art hierarchically above the everyday, subsuming such experiences as merely art-like, falling short in most respects. To this, one might respond that the borders between art and the culture industry and art and non-art has been somewhat questioned and deconstructed in art theory and practice, as well as the philosophical metaphysical justification for their separation, so that it has become possible to think aesthetics in art and aesthetics in everyday life together.

The result of this confluence is both deconstructive and (re)constructive. It is deconstructive in that:

1) There is a the lack of a radical differentiation of aesthetic experience as it pertains to art and also equally a lack of a definite corresponding meaning that pertains to a particular artwork or style or movement or even period of art. That is, there is no ultimate, present aesthetic, nor a corresponding ultimate, present, ideological content in art. This deconstructive tendency can be summarized as follows: I would argue that there is no ideal correlate, that is, between art's sensuality and idea. Furthermore, that there is no necessary correspondence between sign and referent, just productive "play". That art and sport are "intertwined", that is, art is not insular and autonomous, but like language implies another. Moreover-and lending support to the arbitrariness of our games, "forms of life", languages-I contend that art and sport are "locked" within the framework of institutions; that expressive intention is questionable and that formal beauty is not only reserved for art, but other experiences such as sport.

2) On the other hand, my argument is (re)constructive in that this deconstructive tendency leads to a reconstruction of the aesthetic so that it pertains to 
everyday life itself, sport in particular. It is precisely then an art-centered approach that develops this conception. While Melchionne (2011) and Saito (2007) think that art as a model is not necessary to explicate everyday aesthetics, I argue that it is precisely art's engagement with the everyday in the first place and the art-like repose necessary for the appreciation of the everyday in the second place, that one may come to an aesthetic appraisal and conception of sport.

\section{Gumbrecht's Notion that Sport Is Aesthetic}

I have been arguing that insofar as sport may be concerned with an aesthetic concern, there is a formal dimension that can be construed into a formalist theoretical model in order to develop a theoretical parallel between art and sport, if not convergence. Gumbrecht lends further weight to this thesis and in what follows I shall describe his ideas on the matter.

The shared aesthetic trait in art and sport is what Gumbrecht (2006) presents to the reader. Gumbrecht (2006), a leading figure in the philosophy of aesthetics offers in his book, In praise of athletic beauty (2006) a new aesthetics of sport in order to retrieve sport from the margins of intellectual enquiry within the "global academia". He begins by challenging the tendency within the western academy to deny athleticism intellectual praise (the Classical Greeks were an exception). This has occurred because human physicality and related sportive activity has often been pushed to the margins of western cultural life, where it joins others forms of popular culture outside the realm of "high culture". This situation can only be redressed when sport performance is reclaimed as potentially beautiful, and by extension, establishing a case for an aesthetic essence in sport which is tantamount to a formalist project in that an aesthetic dimension can be reduced to-or analysed as-a set of formal properties or an abstract configuration of sorts.

He does this by looking at Kant's notion of disinterest, those moments of aesthetic transcendence resulting in the observer or listener moving into a state of pure appreciation, detached from other dimensions of worldly existence. It is this that creates the beauty of art. Gumbrecht uses the term "focused intensity"-borrowed from the swimmer Pablo Morales (2006: 49)-to describe the disconnectedness both athletes and spectators experience at heightened moments of sport appreciation. The wondrous surprise occurring in the moment of appreciation "can be thought of as a kind of epiphany" (Gumbrecht, 2006: p. 54). Therefore, the aesthetics of sport recalls a kind of artistic inspiration.

Beauty in sport arises from the Greek concept of arête (striving for excellence) and becomes apparent to the appreciative eye. This arête necessitates agon (competition). Characteristic of this beauty is a certain effortlessness and flow"the beautiful athletic movement, resulting in a moment of transfiguration for its appreciator, comes from deep within the athlete and is projected outward" (Gumbrecht, 2006: p. 70).

In the section titled "fascination", by which Gumbrecht means the dimensions 
of interest that compel people to watch sport, an expectation and anticipation of sporting excellence is created (Gumbrecht, 2006). The dimensions of spectator fascination that Gumbrecht discusses include "suffering", "grace" and "timing". Individual suffering in athletic performance is the result of the confrontation of the potential of death. He uses the example of Dempsey, the heavyweight boxer, to illustrate that it was in bruising defeat and suffering that he triumphed, that afforded him public reverence as a champion. The spiritual side expressed in defining "grace" is defined by the image of the great athletes as they appear to move "not from the instructions of the brain but by command from some higher force" (Gumbrecht, 2006: p. 169). Gumbrecht hails today's sprinters and swimmers, linebackers and forwards, as icons of muscular grace. And timing-"good timing... refers to the case of perfect fusion, between a perception of space and the initiation of movement" (Gumbrecht, 2006: p. 198). The interconnectedness of time and space occurs in a way familiar to the arts and is the meeting point of arête and agon. Violence is intrinsic to the competition for space; here one may say that beautiful moments arise, and timing is about avoiding or producing violence. Thus Gumbrecht is finding a cognitive voice for the praising of the athlete, a veneration associated mainly with the artist.

In the final section he makes a case for "gratitude" (Gumbrecht, 2006) being given to the athlete for his or her creation of beauty, via the terms "watching" and "waste". He writes about two aspects of watching sport, namely analysis and communion. Analysis is a more personalized viewing experience whereby sport is watched on television with a critical eye. The communal watching experience ${ }^{3}$ - that Gumbrecht (2006) prefers-occurs at the sport stadium. Here followers are collectively gathered usually in support of a team. Gumbrecht believes that there are moments when the energy of the crowd connects with that of the team and suggests that in this ultimate moment of communion the prospect of collective aesthetic experience is heightened (Gumbrecht, 2006). "Waste" refers to athletes whose lives fell away since their retirement from sport, but this would not indicate that they wasted their time; their subsequent demise is not indicative of waste, but sacrifice. Thus, those of us who have seen beauty in the performance of the sportsperson must be grateful because the potential sacrifice gives to us an awareness and appreciation of joy in our own mortal existence. So Gumbrecht appears to make the case that sport certainly is aesthetic. That the "wow"4 we may feel for a painting correlates as "aesthetic entities" to that of the "wow" we feel for sport. Therefore, an analysis or understanding of sport requires a formalist theoretical perspective as, in the making/constructing of

${ }^{2}$ One may call this "higher force" the subconscious or "great reason" (following Nietzsche). One may note then that the sportsperson and artist need access to a level beyond the conscious level. ${ }^{3}$ I cannot help but feel a sense of communal kingship is established at the theatre as if the audience goes through the drama together. To a lesser extent, the fine arts gallery offers a space of communion, certainly where performance art is concerned, though here, in general perhaps the experience of the gallery is rather more isolated.

${ }^{4}$ This "wow" may take a number of forms depending on the language-game, or "form of life", each incommensurate and none ultimate. 
beauty, sport is composed of a language of sensory artistry.

Applying Gumbrecht's “findings”, Regier (2008: p. 31) analyses Zidane’s winning goal for Real Madrid in the 2002 Champions League final as beautiful. Such a judgment satisfies the following criteria:

1) The goal can be said to be "purposive without purpose" because it is a goal as of its kind with no further function.

2) It represents disinterested beauty-regardless of whom one is supporting one can appreciate the goal.

3) One ought to claim subjective validity universally, no necessary prior cognitive stock is required, that is, contextual knowledge. Though one cannot prove its beauty, the Kantian model is maintained.

Following Gumbrecht, Regier maintains that sport tends to the condition of beauty. In appealing to beauty, one is lead to a formalist-type description of the performance or viewing thereof. This may explain the attraction of sport on both a conscious and sub-conscious level. In other words: while sport seems to be the counteraction if you like to contemplation, Gumbrecht now contemplates it (sport) which in a sense breaks the circle (of the polarity of "action" and "contemplation" [aesthetics]).

The renewed interest and shift to everyday aesthetics and Shusterman's somaesthetics (defined above) combined with the deconstruction, particularly in continental philosophy of the logos and the purported sacredness of art, has lead to a broader conception of art. Furthermore, this shift is characterized by a tendency to move away from metaphysics into what might be termed a Zen-like, pragmatic understanding of life; a movement away from philosophical idealism towards an engagement with bodily, pre-cognitive perceptual (aesthesis) reality; tacit knowledge as opposed to correspondence thinking. Consequently viewing both art and sport as not merely games apart from life, but as part of the fabric of life and culture, that is a "participatory self". In order to make this argument, that is to render what is precognitive, kinaesthetic and non-conceptual conceptual, I have discerned common elements shared by art and sport, namely "play", empathy (Einfühlung), imagination, morality, the ineffable and intransitive ways of knowing. These "concepts" rationalize the idea that art and sport overlap, suggesting new ways of understanding sport derived from art-related aesthetics.

\section{Basic Underpinnings}

Underlining ideas that draw these disciplines together conceptually and develop an account of sport from an arts perspective or rather art-related aesthetics are the following categories:

\subsection{Aesthesis}

This ancient Greek word/concept is derived from a word meaning "to breathe", that is, perception as pneumatic (as involving the soul or spirit), and later became adapted to aspects of the notion of naming Baumgarten's new field of aes- 
thetics and its application to art. Art until then was considered "techne" or craft and mere puppets of political and religious institutions before the secularization and democratization of art and culture (a further such development could lead to acknowledging sport in a similar way reserved for so-called high culture, that is, art).

"Aesthesis" could be understood perceptually in the sense that things breathe themselves "in" and "out", that physicality embodies a vital spirit. Perception is the basis for experience co-joined as it is with mental processes, and is a kind of life-giving breath that leads to pleasure. Hence we can delight in art (visual sense predominantly), music (auditory sense predominantly), in dance (movement predominantly), in sport (generally and predominantly movement). In my estimation this perceptual delight (aesthesis) is not contrary to noesis, because perceptual pattern (including "chaos" as Jackson Pollock "taught")—aestheticspresupposes conceptual pattern ${ }^{5}$ or at least may be interpreted as such. What is clear is that conceptuality and sensuality are interrelated: we speak of movement, rest, shape weight, magnitude, number, and unity in nature, in the arts and in sport. Such terms combine categories of mind with empirical quantities and qualities of the external world.

It is curious that "aesthesis" is not even an entry in the Encyclopedia of Aesthetics (1998) and a number of other encyclopedias and dictionaries of art terms that I consulted. However, I would suggest that it is precisely this concept, namely the pre-cognitive, perceptual and kinaesthetic relationship between the observing subject and perceived object that explains one's resonance with the object, whether it is the art body or the sport body-an orientation towards relating to perceptual experience, to vital presence.

Rancierre's alternative or counter history to European Modernism entitled "aisthesis" (which is the same as the concept under consideration) is a caveat of moments that highlight the visceral, perceptual presence of moments that might have been pivotal to the development of the arts. Ranciere (2013: p. xii) summarizes his project as follows:

...these scenes of thought collected here show how a mutilated statue can become a perfect work; a an image of lousy children the representative of the ideal; somersaulting clowns a flight in the poetic sky; a piece of furniture a temple; a staircase a character; patched overalls a princely garb; the convolutions of a veil a cosmogony, and an accelerated montage, gestures the sensible reality of communism.

Thus Rancierre highlights the aesthetic forms of prosaic life, destabilizing the hierarchies of knowledge and enjoyment. Such moments and forms are ultimately without a determinate concept in order to conceptualize what is a

${ }^{5}$ Traditionally it is unclear whether such pattern is only in nature and its scientific discovery, in the art-object/sports-act and/or "in" the artist/sportsperson's mind and/or only in the consciousness of the reader/interpreter/viewer... 
non-conceptual aspect of our life, that is, perception that never quite reaches "things in themselves". This kind of perception carries with it the meaning of aesthesis: pre-cognitive, sensory experience and appreciation; haptic, tacit, heuristic, kinaesthetic knowledge and experience. In other words, the externality of things-perceptual awareness-symbolically through its bodily appearance speaks of a "form of life". In this respect, Rancierre's analysis of a kind of gymnastics in pantomime, fake Bergere such that "this apparent helter-skelter and disorder, finally, depicts real life in its capricious aspect more precisely that the most intricate drama" (Rancierre quoting Gauteer 2013: p. 83). The material, perceptual fragment of even "low" culture is accorded an influence more substantial than what is perceived as "high" culture, as defining modernism.

I would claim that such a conceptual movement from high art to popular art is a bridge linking art to sport, linking the material fragment, that is perceptual bodily knowledge (aesthesis) within the canon of modernist aesthetics so that "the art of freely combining these patterns is the act of gathering and decomposing them in order to construct pantomimic scenarios that foil expectations and unite what is incompatible" (Rancierre, 2013: p. 90). Rancierre goes on to describe this "corporeal writing" in dance, even applied and decorative arts forms that the painters brush left on the canvas in two dimensions and the sculptures knife fixes in immobile volumes (adapted from Rancierre, 2013). What I think is suggested here is the ineffability of sensation and at the same time an art that serves life wherein poetry, music and dance would reunite in the very body of activity. Cinema (and here Rancierre analyses the example of Charlie Chaplin), for example thus conceived would be seen as a "total art", whereas the fine arts such as painting and sculpture ${ }^{6}$ only suggest vital body movement.

It is precisely sport and its representation or presentation in popular formats that is the primary example in our times of body movement and while this may be obvious, an awareness of its aesthetic dimension may be garnered from its extreme perceptual (aesthesis) skill; sporting games that, like art, became organized during the latter part of the nineteenth century. Might one then not even maintain that secular sports are significant in defining modernism, and specifically in the non-conceptual, perceptual emphasis on its vitality; that art and sport require heightened perceptual awareness?

\subsection{Empathy (Einfühlung)}

In the course of intensive philosophical debates on aesthetics in nineteenth century Germany, Robert Vischer introduced the concept of Einfühlung in relation to art. Theodor Lipps subsequently extended its use from art to visual illusions and interpersonal understanding. While Lipps had regarded Einfühlung as basi-

${ }^{6}$ In Hall's The world as sculpture (1999), he makes the point that to the extent that sculpture has tended towards its own tactility, its everydayness and its physical confrontation, so the world of things are in themselves sculptures. Art and life are not clearly separate. This is one basis for arguing that art is related to other domains of experience. 
cally similar to the old notion of sympathy, Edward Titchner believed it had a different meaning. Hence, he coined the term empathy as its translation. This term came to be increasingly widely accepted, first in psychology and then more generally.

At around this time, Vernon Lee explicated a theory of empathy in art wherein she studied body movements in relation to aesthetic form. She developed an empirical-based empathy theory of art. As she states: "is not what we call the conception of the abstract relation outside as a perception of a concrete relation inside us? The innervation of certain movement, the basis of a movement itself" (in Lanzoni, 2009: p. 330). In these terms, she develops a physiological and emotional response as vital elements for the appreciation of beauty and she conducted her experiments in gallery and museum settings in the 1890s. She showed that there is a kinaesthetic of art reception that moved the body in a manner both emotional and actual. Robert Vischer argued that such movement in art is not simply physiological but psychologically rich involving a projection of movement, bodily feeling and even the self into the object of aesthetic appreciation, an expansive ego-based immersion in the art-object.

For Lee this constituted the confluence of body-mind reactions-that is, while Vischer focused more on feeling derived from, in the main, optical pleasure, Lee's focus is on motoric response mechanisms influenced by aesthetic experience. And this bodily resonance sharpens and focuses the aesthetic repose and contributes to the general well-being-a certain "tactile sense" and "muscular sense" is involved in judging of weight, resistance, impressions of the object that are mirrored by the perceiving subject. This in turn produced a "sense of living in those who experienced it... and gives us the life-enhancing qualities of the object" (Lee in Lanzoni, 2009: p. 339). This draws from Nietzsche's belief that art and aesthetic experience results in a heightened sense of the capacity for lifederived from that which is otherwise beyond the ordinary, everyday life. It requires imaginative projection to see from the others (or perhaps even the artist's) projection and emphasizes in what Merleau-Ponty might describe as lived bodily experience rather than pure abstraction, of play and desire and compassion.

Yet this rare experience can be found in everyday objects and Lee uses the example of a chair and a bowl to show that we somehow intuit and perceive in the object of attention a physical (and mental) "positioning" in relation to it that is a visceral effect which may be empirically measured so that, for example, "spatial dimensions were translations of perceptual modes bound to bodily ${ }^{7}$ extensions" (Anstruther-Thomson, 1924: p. 67). Consequently, harmony and pleasure is a kind of "aesthetic instinct", deeply rooted in the needs of the organism and

${ }^{7}$ Wolfllin held a similar view, namely that "we invest inanimate objects with inward states by analogizing between their physical shape and endowing on the other body posture and mood" (in Podro 1982: XXIV). Moreover, even verbal expression and written poetry is rooted in our ways of speaking which is based on the biological evolution of the tongue, palette, teeth, gut and thorax-we cannot separate mind and body as such. 
leads to well-being.

Worringer in 1908 in his work Abstraction and Empathy takes a different track to Lee. He argues that representational art is comfortable and "objectified self-enjoyment" (Worringer, 1908: p. 16), whereas abstract art thwarted the empathetic impulse producing an unease. Both abstraction and representational art, however, existed on a continuum of self-estrangement, relinquishing autonomy in absorption in the art-object; in the case of abstract art inducing emotional discomfort. For Lee, empathy was just as possible for geometric as for organic forms. One could say much of these discussions centered around the implied energy and movement of shapes and patterns particularly as abstraction began to take root. It seems that a confluence of the haptic and optic requiring the active experience of the individual spectator-and the birth of cinema heralded an emotive projection with the moving narrative and optical "visual music" akin to realistic representational art. The waning of narrative in painting and sculpture via abstraction was perhaps fuelled by the increasingly popular cinematic artsthe moving image.

One can perhaps sum up the fascination for "reaching out" to the aesthetic form as the senses becoming more spiritual and the spirit more sensual. While Robert Vischer found a lexicon of such terms to express this: Aufuhlung (responsive feeling), Nachfuhlung (attentive feeling) and Zufühlung (immediate feeling), it was Einfühlung (empathy) that inspired much discussion. It conjured a resonance between spectator (viewer, listener...) and "object" that permeated perhaps both with a sense of striving, activity, power and energetic repose. Whether this could be grounded as a universal aesthetic-described both physiologically and psychologically - is debatable, and often subsides into mere elitism. It also could be construed as attentiveness to "pure form" and thus falls to the criticism levelled at formalism, or as expressive in been concerned with definite emotional dispositions of the maker and viewer in relation to the aesthetic object, which falls to the "intentional fallacy" and utopian Tolstoian brotherhood through the arts-both of which are contentious.

What is interesting is that the "faculties" for "sympathetic" and "empathetic" responses in humans are neurologically identical (Gladstein, 1984: p. 42) so that the sympathetic and empathetic are similar human experiences even as the former initially held sway in aesthetics. Both, however, are signs that do seem to constitute a universal language both formally and emotionally, for example, we "read" the facial expressions on another person or his/her gestures in communication (cultural differences aside). Nevertheless, empathy (like sympathy) captures a sense of both identification with other (or the aesthetic object) and alienation (as self cannot fully know other).

One may apply this account of Einfühlung to sport with the following considerations:

1) The physiological and psychological basis of aesthetic experience links and encompasses both art and sport. In fact, the way one may apprehend the 
art-object and the sense of dynamic rhythm and dance-like movement as is evident in both participating and viewing sport thus describe similar phenomenon. Our empathetic "instinct" projects into for example the represented figure in art in the same way that one may see in sport and so sense, intuit, perceive and assess what needs to be done in a sport playing context (or what the viewer sees or hopes for or assesses during or after the "event"). Sport is the coordination of the senses in action (and a "thought" precedes action). Through sport we are able to express, communicate and feel invigorated as both body and mind "intermingle".

2) With a) above in mind, one could say that in the communal watching experience (whether on television or live; we also watch while we play), we involve ourselves (as the "play" requires on our part-as player or audience). Thus the playing and viewing of sport is similar to the attentiveness in perceiving an artwork as well as the kinaesthetic dexterity, even whole body movements in a converging and parallel fashion to art such as the literary, where sensitivity to the "weight" and "sound" of words, are required.

Moreover, the dual and yet simultaneous presence of self-estrangement and connection to the sensed object in aesthetic experience perhaps explains both the individual aloneness and communal experience that is often felt when viewing sport-that we are somehow submerged in the game, the ego inflated, our sense of kinship with players and fans heightened-and yet we are all too aware that it is a game, that the athletes are but players and that we exist separate from one another. We might not actually be those sportspeople into whom we empathetically project and through which one may profit with temporary release via entertainment. In a sense, though, one may live vicariously through a sports hero's achievement. For the player, perhaps his/her empathic body-sense while absorbed in the game/art/craft also descends after the extravaganza, when the game is over as even elated victory is temporary (as is defeat).

In this regard, Einfühlung describes both a powerful egoist urge and identification and its demise or lack of conceptual awareness when aesthetic experience and its physiological and psychological base are not circumscribed by culture (when the game is over). In this respect, a tendency towards the aestheticisation of the everyday and the extension of the boundaries of art through considerations of the "living body" (or somo) as well as the lack of a cultural distinction between the everyday and the high seriousness of fine art, it would perhaps be useful to renew theories of Einfuhlung. Hence I resort to referring to it as a basic conceptualization of the art-sport dynamic.

Combining considerations concerning everyday aesthetics, somaesthetics, aesthesis and Einfühlung, we may say that it is the presence of the bodily, of physicality that marks aesthetic experience. At the same time this attentiveness to bodily rapport with the object of aesthetic attention links artistic experience (theory and practice) to the organized, dance-like bodily movements of sport, both as player and viewer. This is achieved as the senses are engaged in assessing 
that which is "external" and in the process of mixing and matching is an aesthetic experience requiring bodily positioning and reaction filtered by the brain and other (living body) functions.

Feelings of awe, fright, love, horror, beauty and so on are because of one's embeddedness and relationship between ourselves and "things". Understanding presupposes a certain intimacy (empathy). Understanding is also not just making sense; it also means learning how to inhabit a new world so that hermeneutics-how to interpret what is there-is a "practical philosophy" which shows itself in action. For Danto it means entering into the history and theory-the hermeneutic circle-of the art world. Though this theory could be construed as a vindication of high art, Shusterman's pragmatist aesthetics by contrast takes an active role in reshaping art, particularly in the direction of awareness of the facile distinction between high and low art and between art and life. One implication is that other aspects of life, such as sport may overlap with art. But most poignantly is that empathy in art and sport is the way we relate, connect and share; it enhances a world consciousness.

\section{3. "Play"}

Eugen Fink (1960) has written extensively on the idea of play. He bases his high praise for the concept on possibly the earliest and most fundamental rendition or expression, arguing for the cosmic symbolism of play, quoting Heraclites (in Krell, 1972: p. 66), who appears to unite the idea of cosmic fire, logos and play in this lengthy but beautiful quote:

...play becomes a cosmic metaphor for the collective appearance and disappearance of things in the space and time of the world. The foaming and frenzied flood of life, which instills in living beings the desire to reproduce is secretly one with the dark wave, which tares at living things away into death. Life and death, birth and dying, womb and tomb, are sisters, one to the other: the propelling power of the totality produces and annihilates, creates and kills, uniting the highest desire and the deepest suffering

Krell notes that such a dramatic view of play informed Nietzsche's philosophy $^{8}$ which repelling the tide of the "metaphysical tradition" wherein being and stasis are emphasized, instead focuses on flux, becoming and playful struggle. In this sense, it is argued that it is the artist and child who are said to play without a goal, to enact via the body and "perform" within a world that is both real and unreal, a game defined by rules (later formulated as institutions) and yet spontaneous and free. Yet the common belief is that play is mere diversionentertainment-a means to refresh oneself for further labour, work or war. However, the early twentieth century work of Huizinga overturns a strict polarity between play and work. He argues that play is also serious and permeates

${ }^{8} \mathrm{I}$ have in mind here his elucidation of the power of Dionysius and the eternal recurrence of the same. 
most activities, because human beings are essentially homoludens, such that education, music, athletics ${ }^{9}$, law and the religious festival are all bound by the same root syllable as is evident in the vocative for Greek in all these domains, namely pai (Krell, 1972: p. 77).

If one acknowledges the ubiquity of play, then metaphysics and the assumed status of transcendental reason, of logos is called into question. Rather, reason itself derives its objects from the carefree joy in the senses, a kind of "pagan" unity with world, whereas unlike technicist "reason", subject and object are not separate. There is what one might call a certain empathy and participatory consciousness, where both truth and illusion configure and reconfigure one another, where beings' essence, as Heidegger put it is "the game itself" (in Elden, 2008: p. 52) - das Spiel selbest. As Heraclites once put it: "eternity or time (aion) is like a child playing a game" (Elden, 2008: p. 48). In this respect, Fink (1960) argues that play is a theatrical enactment or embodiment of the immaterial-a "speculative metaphor of the world" (Fink, 1960: p. 105). Rather than reason as embroiled in measuring, calculating its object-the world, from the perspective of a transcendent subjectivity, itself is becoming (the game unfolds in time) and constitutes subjectivity itself. Even play itself is in a way playing with the player, as if our language plays us, rather than we controlling the world through language.

Such ruminations on play carve out a space wherein joy, delight, fun and pleasure are integral to our interaction in/with the world. Play has a social function, if at times purely imaginative (one might play-act against an imagined "adversary" or "enemy" for example); it does not elevate reflection as above life-experience but enjoins one to become aware of our activity, a certain living impulse and dynamism, a creativity as we "play with work and struggle, love and death. We even play with play" (Fink, 1960: p. 100). One may grimace with pain while running for example (or even in contemplating ${ }^{10}$ ), yet in a sense it is not real pain, it is circumscribed within a particular context or game-a race, solving a problem and so on... Running or contemplation are agreed delusions-ways of relating, creating, communicating even if at first only to the self.

I mentioned the pleasurable aspect as most such imaginative games require real props (i.e. it is not actually "things" in the ordinary sense), real theatre, but most importantly, a joy in appearances (aesthesis), Freud am Schein. It is thus "redeemed from the weight of real life" (Fink, 1960: p. 90); it is a certain freedom and a revelling in the sensory "mask", an Apollonian and Dionysian reverence. Or what Hegel called "the most sublime expression of true seriousness" (in Fink, 1960: p. 105). It is thus no surprise that sport as play began in the ancient games as a kinship with magical rites.

My understanding of the "cosmic" significance of play reveals to me a bi-polarity. On the one hand, play as in aesthetic play (that permeates all fields

${ }^{9}$ Though admittedly athletics does not feature much in his theory.

${ }^{10}$ Could one not conceive "thought" as a kind of movement-certainly metaphorically speaking and obviously physiologically so. 
in varying degrees and ways) is a kind of rhythmic aesthetic redundancy ${ }^{11}$, as imaginative; self-referential; undefined; institutional body-politics; as ineffable and as an incessant need to "think" through forms. On the other hand, play refers beyond its own parameters (a particular game) and suggests a moral code; an "absent" or content; a relationship or interface between different disciplines (such as between art and sport; a form of socializing; as a site where mind and body are fused and as a will that asserts itself in ongoing creative expression that takes innumerable potential forms. These dualities express a certain ambivalence to play-play in art, play in sport-in that it is unclear in what sense "the game" brings people together in a positive or negative sense. Mass aesthetic delusion or hysteria or rhythmic repetitiveness (what I term aesthetic redundancy) is not necessarily a positive thing. On the other hand, imaginative and empathetic projection within the context of life is a desirable form of communication in society, mediated by various games. As communication and on a certain level simply pleasurable entertainment, there is play. One hits the tennis ball in order for there to be a return. Or does one simply want to vanquish one's opponent and thus expect no return? One might make art to say something to someone or a public (or even just to oneself) or is it to glorify? Is sport and art simply a way to assert power? I believe that their power lies in their unifying elements, their way

\footnotetext{
${ }^{11}$ By the phrase "aesthetic redundancy" I wish to connote both a monotonous repetition and the potential for meaningful, creative rhythm circumscribed by rules in the context of play and various games, where outcomes and performance/s are unpredictable. It also refers to the incessant deluge and overflow of images (sounds...) encountered in relation to entertainment and culture. It is unclear what such signs may mean, for their interpretation conforms to their function in a particular game, though signs may change in meaning over time and in different contexts. The veneer of a plot, a story, an unfolding drama would appear to give sense to the deluge of sensory data. While each game may tell a story peculiar to that game, it may also have other ramifications. The point is that to claim control of the story, assuming there is one, is problematic, in which case one "surrenders" to the deluge of sensory stimuli, to give in to "aesthetic redundancy" and the story of the particular game, without resorting to "deep" philosophy, which transmutes into ideology anyhow. On the other hand, could one then be ignorant of not living Socrates' vision to live an examined life? Awareness that these sensory stimuli are aesthetic does lead to thought and vice versa, so that life, mediated by various games, can be more subtle, intransitive or tacit forms of knowing, where we see the borders of a particular game (for example sport or for that matter grooming, sex.... and so on) and another (for example art... or for that matter politics, economics... and so on) give way and then interlink. The method for seeing if this is possible was to use art-related aesthetics and interpret sport based on that perspective. The result is a new interpretation. This practically or perhaps merely theoretically means that neither art nor sport in themselves are dominant paradigms (stories, games, culture...) and therefore linking art and sport is an example that if other domains/games/institutions had to similarly interlink (including perhaps further links with art and sport), then no particular dimension will retain or maintain itself as dominant (like the mere differences in language). And the hope is that out of that, a linkage may register a universal symbol without form (a web?), neither sensual nor conceptual. It is "larger" than any individual and any collective and any one particular game, set of skills, know-how. These are far-reaching possible consequences of linking art and sport. But this only will be if the linkage in question produces a meaningful arrangement/harmony/aesthetics/language in the first place. The problem is can one ever be certain of such a meaning or at least of a particular, conclusive one? (in theory I would say no). That is why the art-act (performance) or the sports-act (performance) is so powerful-it is certainty amidst doubt, and the promise of harmony. Yet art theory and practice has acknowledged the shortsightedness of such an appraisal of art itself or sport for that matter. A deconstruction is necessary in order to lay the foundation for linking with other dimensions of experience.
} 
of connecting people, rather than as divisive activities. One might in this respect recall Kant's sensus communis where subjective and universal dimensions bear on aesthetic judgements and Edgar (2013) applies this further by arguing that this intersubjectivity may be applied to a valuation of sport-in its aesthetic power; its sense of communal belonging and compassion, if at times violently agonistic. In any event, playing together as it were appears to bring unity.

In summary, "play" perhaps more so than other models for the world-Thales and water symbol; Plato's light symbol; Hegel and "spirit", Schopenhauer and "will"-is overturned somewhat by the concept of "play" suggesting a metaphysics beyond metaphysics. In other words emphasis is on transient being or rather, becoming; noble struggle and a tacit form of knowing, that which is beyond and unites the extremities of life and death as Heraclites beautifully expressed and with which I introduced the concept. In short: play is a creative form of individual and social meaning-making on a global scale.

Whether one is speaking of pre-cognitive perceptual awareness (aesthesis), Einfühlung (empathy) or "play", one can just as well say that in art and sport as with other games, there is a certain physicality or mediation devices that intercede between "reality" and the perceiving and/or creative consciousness/body. Thus art and sport reveal as much as they conceal without there being a known "reality" (or "ultimate" reality), even with the overlapping and linking of say, art and sport. Nevertheless, this is not to say that such a linkage does not at least theorize a new kind of hermeneutics that portend to an enhanced life-praxis. I will now suggest one implication of this theoretical overlap, although it eschews extra-aesthetic meanings somewhat, a kind of "sabbath" from ordinary life as Edgar (2013) writes, but nevertheless argues for the formal and aesthetic overlap of art and sport, namely that teaching art to sports persons will enhance and improve their sports performance.

\section{Conflicts of Interest}

The authors declare no conflicts of interest regarding the publication of this paper.

\section{References}

Anstruther-Thomson, C. (1924). Art and Man: Essays and Fragments with an Introduction by Vernon Lee. London: Bodley Head.

Best, D. (1974). Expression in Movement and the Arts. London: Lepus.

Best, D. (1978). Philosophy and Human Movement. London: Allen \& Unwin.

Best, D. (1979). Art and Sport. Journal of Aesthetic Education, 14, 69-80. https://doi.org/10.2307/3332478

Best, D. (1986). Sport Is Not Art: Professor Wertz's Aunt Sally. Journal of Aesthetic Education, 20, 95-98. https://doi.org/10.2307/3332697

Cordner, C. (1988). Differences between Sport and Art. Journal of the Philosophy of Sport, 15, 31-47. https://doi.org/10.1080/00948705.1988.9714459 
Dowling, C. (2010). The Aesthetics of Daily Life. British Journal of Aesthetics, 50, 226-242. https://doi.org/10.1093/aesthj/ayq021

Edgar, A. (2013). The Beauty of Sport. Ethics and Philosophy, 7, 100-120.

Elden, S. (2008). Eugen Fink and the Question of the World. Parrhesia, 2, 48-59.

Fink, E. (1960). The Ontology of Play. Philosophy Today, 4, 95-109. https://doi.org/10.5840/philtoday19604229

Gladstein, J. B. (1984). The Historical Roots of Contemporary Empathy Research. Journal of the History of Behavioral Sciences, 20, 38-59. https://doi.org/10.1002/1520-6696(198401)20:1<38::AID-JHBS2300200106>3.0.CO;2-1

Gumbrecht, H. U. (2006). In Praise of Athletic Beauty. London: Cambridge University Press.

Gumbrecht, H. U. (2006). In Praise of Athletic Beauty. Sport, Education and Society, 13, 239-246.

Hall, J. (1999). The World as Sculpture: The Changing Status of Sculpture from the Renaissance to the Present Day. London: Chatto \& Winduc.

Irvin, S. (2008). The Pervasiveness of the Aesthetic in Ordinary Experience. British Journal of Aesthetics, 48, 29-44. https://doi.org/10.1093/aesthj/aym039

Krell, D. F. (1972). Towards an Ontology of Play: Eugen Fink's Notion of Spiel. Research in Phenomenology, 2, 63-93. https://doi.org/10.1163/156916472X00045

Kupfer, J. (2001). Perfection as Negation in the Aesthetics of Sport. Journal of the Philosophy of Sport, 28, 16-31. https://doi.org/10.1080/00948705.2001.9714598

Lanzoni, S. (2009). Practicing Psychology in the Art Gallery: Vernon Lee's Aesthetics of Empathy. Journal of the History of Behavioural Sciences, 45, 330-354. https://doi.org/10.1002/jhbs.20395

Melchionne, K. (2011). Aesthetic Experience in Everyday Life: A Reply to Dowling. British Journal of Aesthetics, 56, 437-442. https://doi.org/10.1093/aesthj/ayr034

Podro, M. (1982). The Critical Historians of Art. London: Yale University Press.

Ranciere, J. (2013). Aisthesis: Scenes from the Aesthetic Regime of Art (Translated by Paul, P.). London and New York: Verson.

Ratiu, D. (2013). Remapping the Realm of Aesthetics: On Recent Controversies about the Aesthetic and the Aesthetic Experience in Everyday Life. Estetika, 50, 3-26.

Regier, A. (2008). Judgement and Experience in the Language of Confessional Sports. Sport in History, 28, 26-38. https://doi.org/10.1080/17460260801889194

Reid, L. A. (1970). Sport, the Aesthetic and Art. British Journal of Educational Studies, 18, 245-258. https://doi.org/10.1080/00071005.1970.9973287

Saito, Y. (2007). Everyday Aesthetics. Oxford: Oxford University Press. https://doi.org/10.1093/acprof:oso/9780199278350.001.0001

Shusterman, R. (2008). Body Consciousness: A Philosophy of Mindfulness and Somaaesthetics. New York: Cambridge University Press. https://doi.org/10.1017/CBO9780511802829

Welsch, W. (2005). Sport-Viewed Aesthetically and Even as Art? In A. Light, \& J. M. Smith (Eds.), The Aesthetics of Everyday Life (pp. 135-155). New York: Columbia University Press.

Wertz, S. K. (1984). A Response to Best on Art and Sport. Journal of Aesthetic Education, 18, 105-108. https://doi.org/10.2307/3332634

Worringer, W. (1908). Abstraction and Empathy: A Contribution to the Psychology of Style (4th ed. 1980, Translated by Bullock, M.). New York: International University Press. 